\title{
Toxic and metabolic encephalopathies: iconographic essay"
}

Encefalopatias tóxicas e metabólicas: ensaio iconográfico

\section{Eric Mendonça Bimbato ${ }^{1}$, Amanda Gontijo Carvalho ${ }^{2}$, Fabiano Reis ${ }^{3}$}

Bimbato EM, Carvalho AG, Reis F. Toxic and metabolic encephalopathies: iconographic essay. Radiol Bras. 2015 Mar/Abr;48(2):121-125.

Abstract Generally, toxic-metabolic diseases affecting the central nervous system can hardly be differentiated just on the basis of their clinical presentation. However, some typical neuroradiological features can guide the correct diagnosis. In this context, magnetic resonance imaging is an important tool which, in association with clinical and laboratory data, can establish an early and specific treatment. The present pictorial essay with selected cases from the archives of the authors' institution describes imaging findings which might help in the etiologic diagnosis of toxic-metabolic diseases.

Keywords: Magnetic resonance imaging; Intoxication; Encephalopathy; Metabolic diseases.

Resu mo As doenças toxicometabólicas do sistema nervoso central geralmente são de difícil diferenciação apenas pelo quadro clínico. Entretanto, existem algumas características neurorradiológicas típicas que podem orientar o diagnóstico correto. Neste sentido, a ressonância magnética é uma ferramenta importante que, junto ao quadro clinicolaboratorial, auxilia na instituição de uma terapêutica precoce e específica. Este ensaio iconográfico com casos selecionados dos arquivos da instituição dos autores tem como objetivo demonstrar achados de imagem que possam auxiliar no diagnóstico etiológico das doenças toxicometabólicas.

Unitermos: Ressonância magnética; Intoxicação; Encefalopatia; Doenças metabólicas.

\section{INTRODUCTION}

Toxic-metabolic diseases constitute a group of conditions that, by different pathophysiological changes, lead to acute or chronic central nervous system (CNS) functional disorders. Different situations can modify in any way the CNS functioning, among them the use of drugs and recreational substances, deficiency syndromes, and systemic metabolic disorders ${ }^{(1)}$.

In some situations, such diseases may present with typical neuroradiological characteristics. A definite diagnosis depends on clinical and laboratory tests findings correlation.

The present pictorial essay, with cases selected from the didactic archives of the authors' institution with images acquired over the last 15 years, was aimed at illustrating neuroradiological findings in toxic-metabolic diseases, which allow for the diagnosis of the specific causes of the condition. Imaging features such as affected anatomical sites and signal and contrast-enhancement patterns at magnetic resonance imaging (MRI) in association with clinical and labo-

* Study developed at Universidade Estadual de Campinas (Unicamp), Campinas, SP, Brazil.

1. MD, Resident of Radiology and Imaging Diagnosis, Universidade Estadual de Campinas (Unicamp), Campinas, SP, Brazil.

2. Graduate Student of Medicine, School of Medical Sciences, Universidade Estadual de Campinas (Unicamp), Campinas, SP, Brazil.

3. PhD, Professor, Department of Radiology and Imaging Diagnosis, Professor Responsible for the Division of Neuroradiology, Department of Radiology and Imaging Diagnosis, Universidade Estadual de Campinas (Unicamp), Campinas, SP, Brazil.

Mailing Address: Dr. Fabiano Reis. FCM-Unicamp - Departamento de Radiologia. Rua Tessália Vieira de Camargo, 126, Cidade Universitária Zeferino Vaz. Caixa Postal: 6111. Campinas, SP, Brazil, 13083-887. E-mail: fabianoreis2@gmail.com.

Received September 16, 2013. Accepted after revision February 10, 2014. ratory data may be useful to establish the etiological diagnosis.

The study project was approved by the Committee for Ethics in Research of Universidade Estadual de Campinas.

\section{WERNICKE ENCEPHALOPATHY}

Wernicke encephalopathy is an acute neuropsychiatric condition resulting from thiamine deficiency. The classic triad of ocular abnormality, ataxia and mental confusion is observed in only $16 \%$ of patients.

Thiamine plays an essential role in the correct functioning of the biochemical pathways of the brain. Although the thiamine deficiency is classically associated with alcoholism, any condition involving nutritional imbalance and lasting for more than 2-3 weeks may lead to depletion of thiamine reserves, causing cerebral lesions in vulnerable (thiamine-dependent) regions such as diencephalon and brainstem. Besides alcoholism, some other conditions may develop with thiamine deficit, namely, hyperemesis gravidarum, anorexia nervosa, refeeding after starvation, thyrotoxicosis, malabsorption syndromes (including those resulting from reduction gastroplasty) hemodialysis, peritoneal dialysis, acquired immunodeficiency syndrome, postoperative vomiting following gastroplasty ${ }^{(1,2)}$.

The presumptive diagnosis might be based on the evaluation of thiamine levels by direct analysis of thiamine pyrophosphate in erythrocytes, high-performance total blood liquid chromatography or by erythrocyte transketolase activity test. One might also utilize chromatography to analyze the levels of thiamine, thiamine mono- and diphosphate in human erythrocytes. MRI is considered the most relevant 
method to confirm the diagnosis, with $53 \%$ sensitivity and 93\% specificity. Typically, the T2-weighted FLAIR sequence demonstrates hypersignal on paraventricular regions of the thalami, hypothalamus, mammillary bodies, periacqueductal region, floor of the fourth ventricle and paravermal cerebellum region (Figure 1); At the diffusion-weighted sequence, one can observe diffusion restriction in the thalami. More atypical lesions might be seen in the cortex and in the splenium of the corpus callosum ${ }^{(2,3)}$.

\section{HEPATIC ENCEPHLOPATHY}

Hepatic encephalopathy is a potentially reversible neuropsychiatric syndrome that may present in patients with advanced chronic liver disease or even in acute liver failure.

At MRI T1-weighted sequences, the effect of paramagnetic manganese is highlighted. Bilateral and symmetrical hypersignal is observed on the globus pallidus, putamen, subthalamic regions, substantia nigra and adenohypophysis ${ }^{(4)}$ (Figure 2).

\section{OSMOTIC DEMYELINATION SYNDROME}

Is a demyelinating disease, generally associated with hydroelectrolytic disorder, particularly in cases of rapid hyponatremia correction. Chronic use of alcohol, prolonged use of diuretics, extensive burns, severe liver disease, among
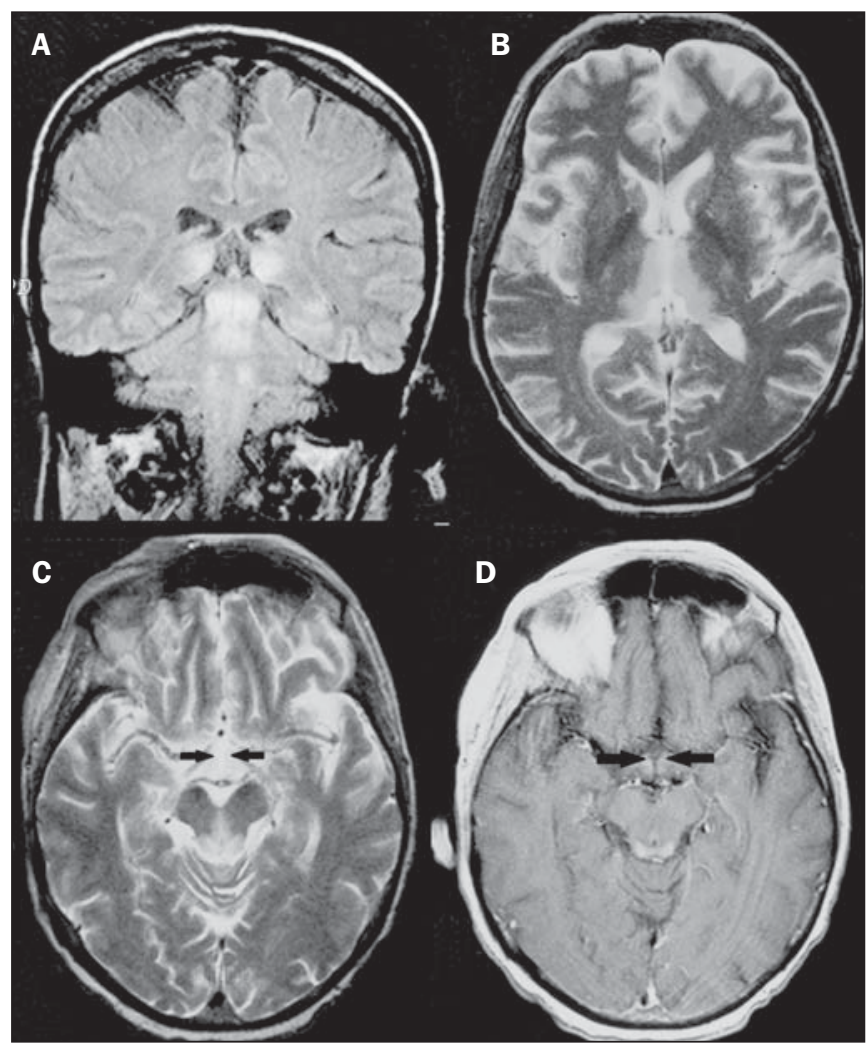

Figure 1. Wernicke syndrome. Female, 47-year-old patient. Coronal FLAIR (A) and axial T2-weighted (B,C) images show hypersignal foci in the periacqueductal gray substance, thalami in paramedian region, mammillary bodies (arrows), tectum and tegmentum of the mesencephalon. Contrast-enhanced T1-weighted image (D) demonstrates enhancement of mammillary bodies (arrows) and tectum of the mesencephalon. others represent risk factors for development of osmotic demyelination syndrome ${ }^{(5)}$.

MRI T1-weighted sequences may demonstrate a subtle hyposignal on the basal nuclei and on the pontine region, with no change in the periphery ${ }^{(1)}$. At T2-weighted FLAIR sequences, there is hypersignal on the central portion of the pons, with no change in the periphery (Figure 3); additionally, foci of hypersignal may be observed in the basal nuclei, thalami and white matter of the brain hemispheres ${ }^{(1,5)}$. As associated with clinical and laboratory aspects suggestive of osmotic demyelination, such findings allow for a reliable diagnosis.

\section{METHANOL}

Methanol intoxication results from accidental ingestion of products containing methanol or ingestion as a method

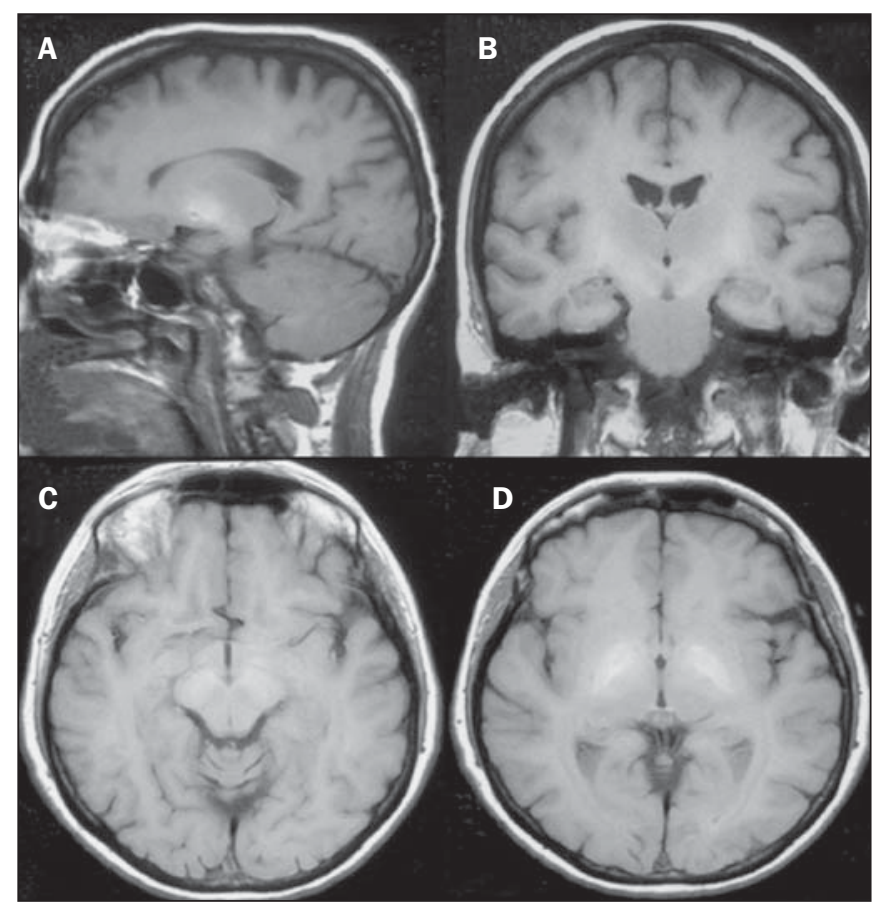

Figure 2. Hepatic encephalopathy by $C$ virus. Female, 69 -year-old. At non-contrast-enhanced T1-weighted image areas of hypersignal are visualized on the region of the globus pallidus, subthalami and base of the cerebral peduncles.

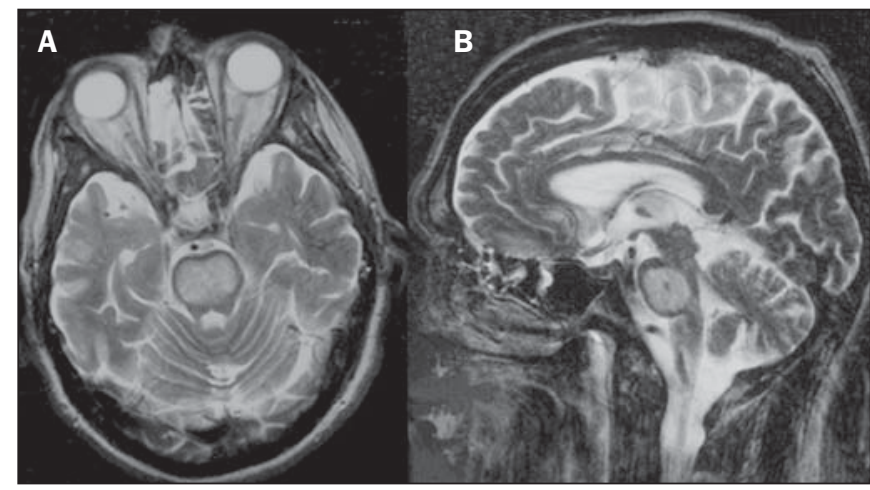

Figure 3. Osmotic demyelination syndrome. Male, 49-year-old patient. At T2 weighted axial (A) and sagittal (B) images, area of hypersignal is observed on the pons, with preserved signal in the periphery. 
of attempting suicide. The end product of methanol metabolism is formic acid, responsible for damages to the optic nerves and brain ${ }^{(6,7)}$. In the suspicion of acute intoxication, a detailed evaluation of the degree of involvement and possible sequelae requires the utilization of MRI, including a study of the optic tract ${ }^{(1)}$.

As a more typical, but nonspecific finding, the presence of bilateral putaminal necrosis is observed with symmetrical hypersignal on T2-weighted, FLAIR sequences ${ }^{(1,6)}$ (Figure 4). In some cases, association with hemorrhages may be observed. Other findings which may be present in severe intoxication include: intraventricular hemorrhage, cerebellar necrosis, diffuse cerebral edema and optic nerve necro$\mathrm{sis}^{(1)}$. At proton spectroscopy, lactate-related reversed peak at $1.3 \mathrm{ppm}$ and decreased $\mathrm{N}$-acetylaspartate levels (as a result from the neuronal/axonal damage to this area) was observed.

\section{WILSON'S DISEASE}

It is an autosomal, recessive hereditary anomaly characterized by toxic accumulation of copper in the body. Copper deposition may occur in the CNS.

Cranial MRI findings are variable, but the most common ones include predominantly symmetrical alterations involving the putamens (particularly in the most external portion), with hypersignal on T2-weighted images ${ }^{(8)}$ (Figure 5). In some patients, areas of hyposignal may be observed on T2-weighted spin echo images, in these grey matter nuclei histopathologically related to iron compound deposits. Other grey matter sites that may be affected include globus pallidus, claustrum and subthalamic nucleus.

In some cases, the "panda face sign" may be found in the mesencephalon, corresponding to hyperintense tegmental lesions associated with normal signal of the red nuclei and

Figure 4. Methanol intoxication. Female, 25-year-old patient. Bilateral, symmetrical putaminal hypersignal on T2-weighted FLAIR image (A) diffusion restriction, hypersignal on diffusionweighted image (B) and hyposignal on ADC map (C). Hyperintense corticosubcortical lesions are observed in the occipital lobes with diffusion restriction. Proton spectroscopy with $135 \mathrm{~ms}$ TE shows lactate-related reversed peak around $1.3 \mathrm{ppm}$, besides decreased $\mathrm{N}$-acetylaspartate (NAA) levels at 2.0 ppm.

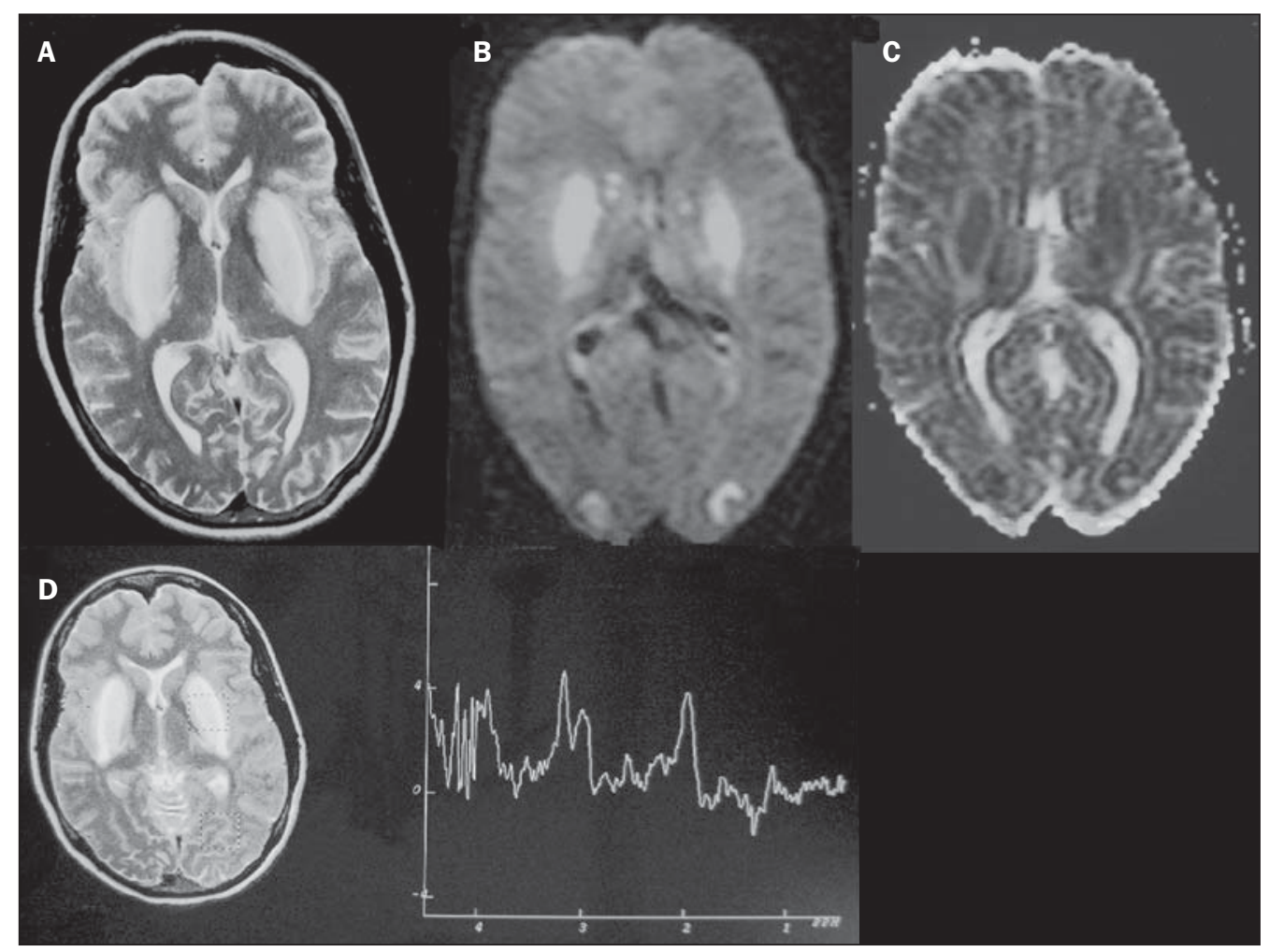

Figure 5. Wilson's disease. Female, 20-year-old patient. Lesions with hypersignal on FLAIR (A) in the tegmentum of the mesencephalon and periacqueductal and colliculi. Also, foci of hyposignal are observed on FAIR and T2-weighted images of the putamens and caudate nuclei heads.

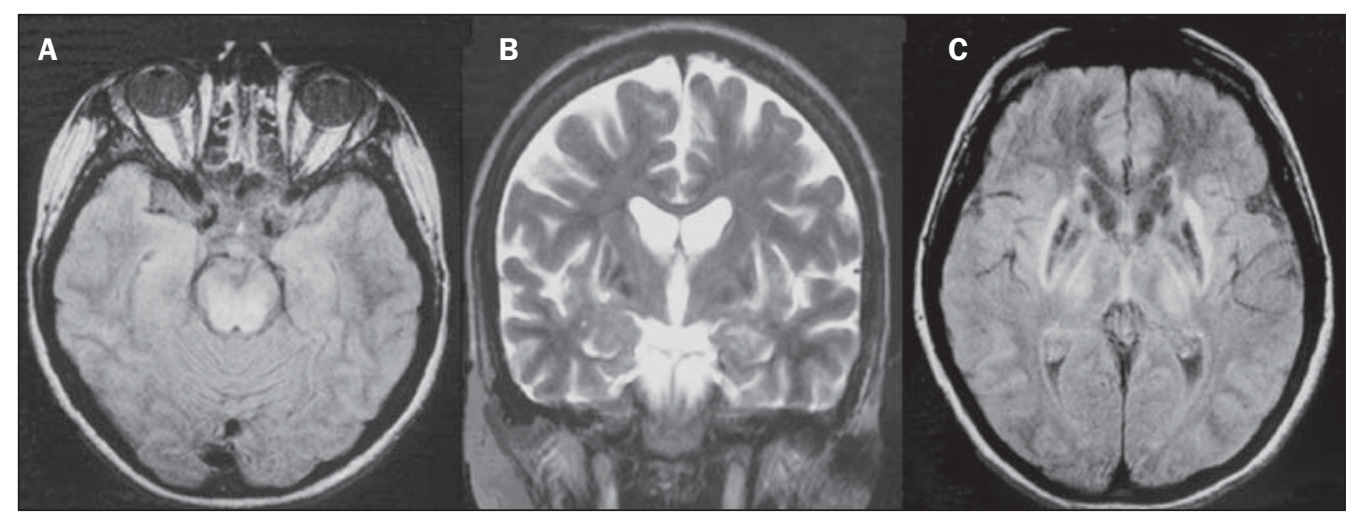


hyposignal on the superior colliculus ${ }^{(9)}$. Additionally, in cases where the disease progresses with liver failure, spontaneous hypersignal may be seen on T1-weighted sequences in the globus pallidus (as a result of manganese accumulation). White matter lesions may be found, particularly in the cortical-subcortical transition in the frontal and parietal lobes.

\section{COCAINE}

Cocaine abuse may lead to myelin destruction with development of vacuoles. In such cases, there may be an extensive involvement of the brain hemispheres (white matter) and cerebellum which may extend toward the white matter tracts of the brainstem. However, most frequently cocaine abuse is associated with vascular complications such as vasospasm and vasculitis, and may cause ischemic lesions in the basal nuclei region ${ }^{(10)}$.

Chronically, users may present with atrophy and multiple, asymptomatic microvascular lesions characterized by hyperintense foci corresponding to the subcortical substance of the insulae and small lacunar foci of sequelae in the region of the middle cerebral artery at T2-weighted FLAIR sequences (Figure 6).

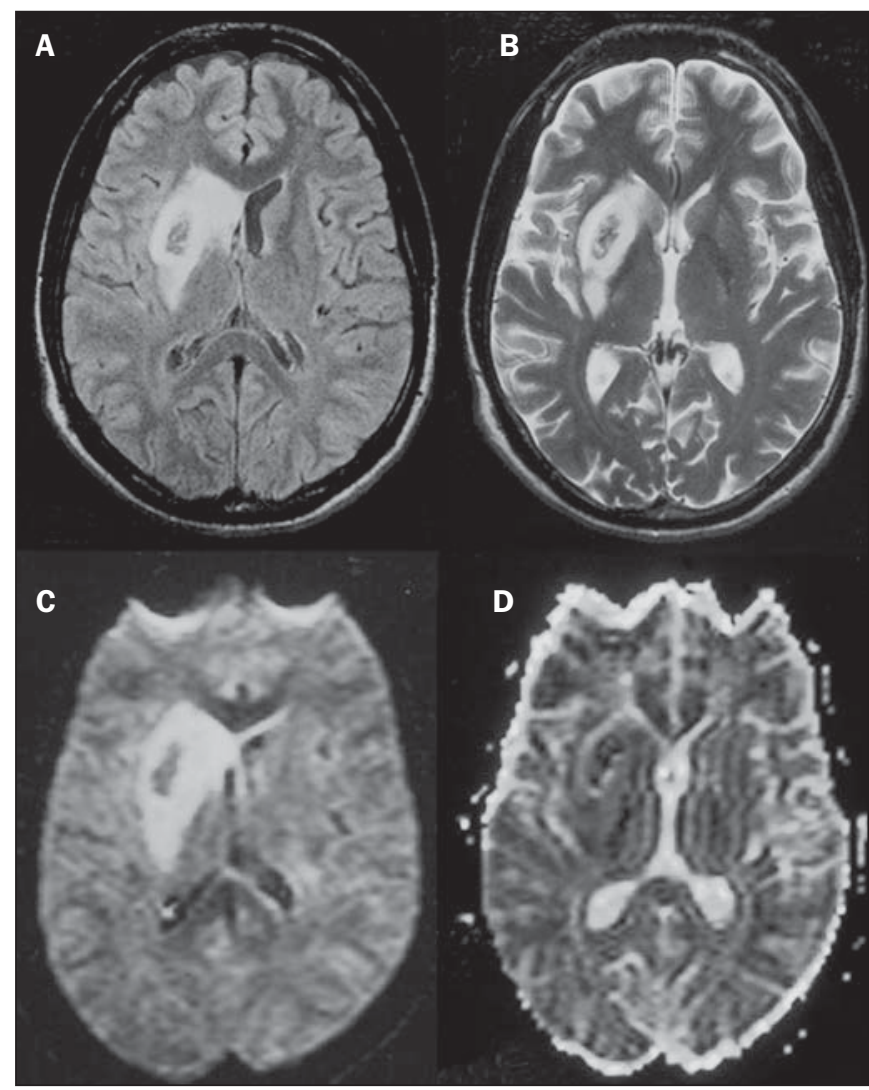

Figure 6. Ischemic stroke/arteritis with infarction caused by use of cocaine Male, 21-year-old patient. Lesions are present in the putamen, caudate nuclei head and anterior leg of the internal capsule at right. Presence of area of hypersignal on T2-weighted FLAIR image, with a focus of putaminal hyposignal intensity (hemorrhage) (A,B). Diffusion-weighted image demonstrates hypersignal (C) and at the ADC map (D) there is hyposignal, except on the putaminal area of hemorrhagic transformation, with hyposignal on diffusion-weighted image and on the ADC map.

\section{VITAMIN B 12 DEFICIENCY}

Vitamin B12 deficiency manifestations may be associated with a classical condition characterized by megaloblastic anemia associated with neurological symptoms resulting from inappropriate vitamin ingestion, malabsorption (particularly in patients with gastric alterations) or other conditions which lead to such a deficiency. Neurological symptoms include polyneuropathy, myelopathy and optic neuropathy. The laboratory diagnosis is made by cyanocobalamine or homocysteine testing and urinary metylmalonic acid excretion testing ${ }^{(11,12)}$.

At anatomopathological microscopy myelin and axonal vacuolation is observed. There is a selective degeneration of posterior and lateral funicles, most commonly affecting the cervical and/or thoracic spine ${ }^{(1)}$. MRI T1-weighted sequences demonstrate mild thickening of the spinal cord, and T2weighted sequences demonstrate symmetrical hypersignal of posterior and lateral funicle of the spinal cord or at least one of the funicles isolatedly ${ }^{(1,11)}$ (Figure 7). In this context, the MRI findings correlation with clinical-laboratory data is useful for the diagnosis.

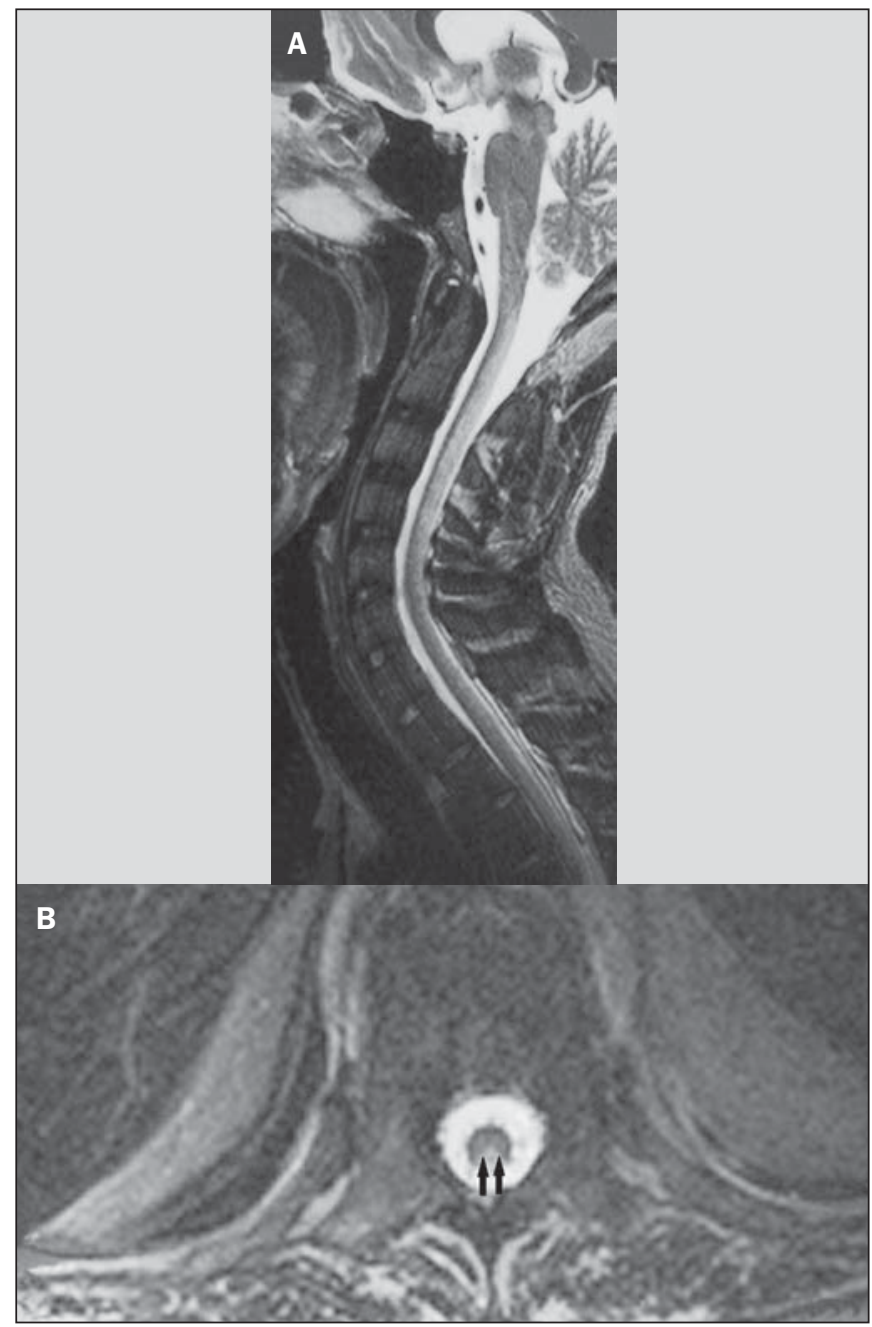

Figure 7. Vitamin B12 deficiency. Sagittal, T2-weighted image (A) with posterior hypersignal on the spinal cord continuously extending along the whole cervical medulla and seen on T2-weighted image (B) in the posterior funicle (arrows). 


\section{ACCUMULATION OF MANGANESE IN PROLONGED DIALYSIS TREATMENT}

Normally reported levels of manganese in the brain exceed plasma levels by $>100$-fold, and manganese transport channels include transferrin-dependent binding receptors. The main manganese excretory pathway is the biliary tract, and the urinary excretion is scarcely significant.

In patients presenting with manganese accumulation, the most frequent finding at MRI T1-weighted sequence is bilateral, relatively symmetrical hypersignal on the basal nuclei, particularly in the globus pallidus and also in the striate nucleus. This may be associated with the abundance of transferrin receptors particularly in the basal nuclei. Related symptoms may vary, and besides myoclonus, parkinsonism is most frequently observed ${ }^{(13)}$.

Manganese accumulation in the CNS is also frequently present in patients with hepatic encephalopathy, in those submitted to parenteral nutrition, and in those with portosystemic venous shunt (either congenital or acquired).

Recent studies have reported manganese accumulation in the CNS (basal nuclei hypersignal on T1-weighted images - Figure 8) and respective symptoms in patients with chronic renal failure submitted to prolonged dialysis treatment. The reason for such accumulation is still uncertain, but it seems there is correlation with manganese transport channels dysfunction induced by dialysis treatment. The in-

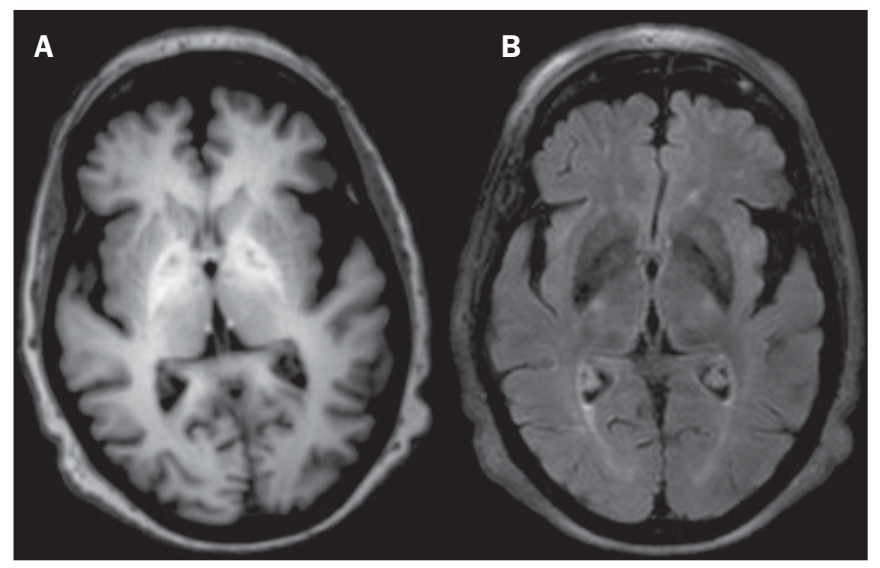

Figure 8. Patient with chronic renal failure undergoing prolonged dialysis treatment did not present hepatopathy. Axial T1-weighted image (A) identifying confluent foci of hypersignal in the globus pallidus at T1-weighted image. Axial FLAIR image(B) with hyposignal in the lenticular nucleus. creased ingestion of compounds with this element can also be observed in these patients ${ }^{(13)}$.

\section{CONCLUSION}

MRI is a quite useful tool to narrow the range of differential diagnoses (in some cases it can even define the specific causes) in patients with toxic-metabolic diseases and compromise of the CNS. The recognition of such imaging patterns is quite useful for the radiologist, allowing for early diagnosis and treatment. Additionally, it guides the clinician to request appropriate laboratory tests capable of corroborating the diagnosis.

\section{REFERENCES}

1. Silva CJ, Rocha A.J. Encefalopatias tóxicas, nutricionais e neurometabólicas adquiridas. In: Rocha AJ, Vedolin L, Mendonça RA, organizadores. Encéfalo. $1^{\mathrm{a}}$ ed. Rio de Janeiro, RJ: Elsevier; 2012. p. 247-88.

2. Zuccoli G, Siddiqui N, Cravo I, et al. Neuroimaging findings in alcohol-related encephalopathies. AJR Am J Roentgenol. 2010;195: 1378-84.

3. Zuccoli G, Pipitone N. Neuroimaging findings in acute Wernicke's encephalopathy: review of the literature. AJR Am J Roentgenol. 2009; 192:501-8.

4. Rovira A, Alonso J, Córdoba J. MR imaging findings in hepatic encephalopathy. AJNR Am J Neuroradiol. 2008;29:1612-21.

5. Howard SA, Barletta JA, Klufas RA, et al. Best cases from the AFIP: osmotic demyelination syndrome. Radiographics. 2009;29:933-8.

6. Blanco M, Casado R, Vázquez F, et al. CT and MR imaging findings in methanol intoxication. AJNR Am J Neuroradiol. 2006;27: 452-4.

7. Arora V, Nijjar IBS, Multani AS, et al. MRI findings in methanol intoxication: a report of two cases. Br J Radiol. 2007;80:e243-6.

8. King AD, Walshe JM, Kendall BE, et al. Cranial MRI imaging in Wilson's disease. AJR Am J Roentgenol. 1996;167:1579-84.

9. Sinha S, Taly AB, Prashanth LK, et al. Sequential MRI changes in Wilson's disease with de-coppering therapy: a study of 50 patients. Br J Radiol. 2007;80:744-9.

10. Filley CM, Kleinschmidt-DeMasters BK. Toxic leukoencephalopathy. N Engl J Med. 2001;345:425-32.

11. Ravina B, Loevner LA, Bank W. MR findings in subacute combined degeneration of the spinal cord: a case of reversible cervical myelopathy. AJR Am J Roentgenol. 2000;174:863-5.

12. Naidich MJ, Ho SU. Case 87: Subacute combined degeneration. Radiology. 2005;237:101-5.

13. da Silva CJ, da Rocha AJ, Jeronymo S, et al. A preliminary study revealing a new association in patients undergoing maintenance hemodialysis: manganism symptoms and T1 hyperintense changes in the basal ganglia. AJNR Am J Neuroradiol. 2007;28:1474-9. 